ZOOLOGY.-Seven new genera of echinoderms. ${ }^{1}$ Austin H. Clark, National Museum.

The past ten years has witnessed an activity in the study of the echinoderms far surpassing that of any previous decade. In every class important and comprehensive memoirs, many of them monographic in scope, have been published which include more or less complete revisions of genera, of families, and of higher groups. Little by little the former wide differences of opinion in regard to the internal systematic arrangement in each class have disappeared, and today such diversity as exists chiefly relates to the refinement of generic limits and the allocation of a few anomalous types.

Along these lines there is still much work remaining to be done, and it is in the hope of throwing additional light on certain obscure points that I am calling attention to the following four crinoid and three starfish types which appear to me to be well worthy of generic rank.

\title{
Comatonia, new genus
}

Genotype.-Actinometra cristata (P. H. Carpenter, MS.) Hartlaub, 1912.

A genus of Capillasterinae (Comasteridae) in which the size is small; there are 10 arms only; the cirri are not excessively slender; there are no carinate processes on the basal segments of the proximal pinnules; terminal combs occur only on the pinnules of the first pair $\left(\mathrm{P}_{1}\right.$ and $\left.\mathrm{P}_{2}\right)$, from one or both of which they may be absent; the combs usually arise about, or within, the proximal third of the pinnule, and are composed of exceptionally large rounded teeth which usually much exceed in height the lateral diameter of the segments which bear them; the fourth-seventh brachials bear prominent spinous median knobs or keels; usually one or more of the earlier segments of $P_{1}$ are twice as long as broad, or even longer.

The only species of this genus, Comatonia cristata (Hartlaub), ranges from North Carolina to Key West, Florida, in from $7 \frac{1}{2}$ to 132 fathoms.

\section{Austrometra, new genus}

Genotype.-Oligometra thetidis H. L. Clark, 1909.

This new genus of Colobometridae is most closely related to Analcidometra, with which it agrees in possessing expanded genital pinnules, a character not known elsewhere in the family. Both Austrometra

${ }^{1}$ Published with the permission of the Secretary of the Smithsonian Institution. 
and Analcidometra are related to Oligometrides more closely than to any other type.

The third-fifth segments of the genital pinnules are more or less expanded to protect the genital glands; there is a single median transverse ridge of moderate height on the cirrus segments; $\mathrm{P}_{1}$, though longer and stouter than $\mathrm{P}_{2}$, is not exceptionally so.

A ustrometra thetidis (H. L. Clark), the only species of the genus, occurs off the coast of New South Wales in 55 to 56 fathoms.

Cotylometra, new genus

Genotype.-Oligometra gracilicirra A. H. Clark, 1908.

This genus of Colobometridae in general resembles Oligometra; but there are 30 or more cirrus segments of which only the basal bear transverse ridges, these after the proximal fourth of the cirrus transforming into very long dorsal spines, and $\mathrm{P}_{2}$ has at most 12 segments instead of at least 15 .

The single species of this genus, Cotylometra gracilicirra (A. H. Clark), ranges from the Andaman Islands to the Malay Archipelago and the Philippine Islands in from 44 to 49 fathoms.

\section{Daidalometra, new genus}

Genotype.-Antedon hana A. H. Clark, 1907.

A genus of Thalassometrinae (Thalassometridae) in which the centrodorsal is small, low, hemispherical or thick discoidal, the broad dorsal pole beset with irregular rather long spines, the sides bearing 10 closely approximated columns of cirrus sockets of from one to three (usually two) each; the cirri are XII-XX, 51-75, slender, from about one-half to three-fourths as long as the arms; the longer proximal segments are usually about three times as long as broad; the basal three or four segments bear dorsally a fine median carination ending distally in a small but prominent spine; the disk is moderately plated; the division series and arms in general are as in Stenometra, but the arms are only from 10 to 12 in number, and the earlier brachials have only a faint low median keel; the pinnules are as in Stenometra.

Of the two species referable to this genus, one, Daidalometra hana (A. H. Clark), occurs off southwestern Japan in between 107 and 139 fathoms; the other, Daidalometra acuta (A. H. Clark), was dredged south of Timor in 40 fathoms.

Mariaster, new genus

Genotype.-Johannaster giganteus Goto, 1914.

This new genus belongs to the subfamily Goniasterinae of the family Goniasteridae.

The general form is stellato-pentagonal, with greatly produced, narrow, evenly tapering rays which are somewhat more than two and one 
half times as long as the distance from their base to the center of the disk. The size is very large, up to $\mathrm{R}=338 \mathrm{~mm}$., $\mathrm{r}=87 \mathrm{~mm}$.; $\mathrm{R}: \mathrm{r}=3.9$ to $4.8: 1$.

The abactinal plates are very numerous, irregularly polygonal, largest in the radiating papular areas and along the center of the arms, diminishing in size slightly toward the center of the abactinal surface and very markedly toward the superomarginals bordering the disk and the proximal third of the arms; on the outer two thirds of the arms the abactinal plates are subequal, irregularly polygonal; an irregular carinal row of plates is sometimes traceable from the outer half of the disk along the arms.

The madreporic plate, which is large, conspicuous, and polygonal, is situated near the center of the abactinal surface and is covered with very fine striae which radiate from the center.

The abactinal plates are uniformly covered with crowded granules, which are much finer than those on the actinal intermediate plates.

The papulae are segregated in conspicuous petaloid areas which extend from a central papular region and radiate onto the arms, reaching nearly to the middle of the latter.

Many of the plates in the papular areas bear small pedicellariae, of which there may be as many as three or four on the larger plates; the plates of the interradial areas also bear pedicellariae, though here they are much less numerous.

The superomarginals increase gradually both in length and in breadth from the center of the interbrachial are to the arm bases; in the interbrachial are they are confined to the side wall of the body and overhang the inferomarginals; on the arm bases they become more recumbent, so that a greater part of their breadth (about two thirds) lies on the dorsal surface. Pedicellariae, sometimes three or four to a plate, occur in the interbrachial ares, but they gradually become less frequent and are rare in the distal half of the arms.

The inferomarginals increase in length, but decrease in breadth, from the center of the interbrachial arc to the arm bases. In the interbrachial are they lie well within the actinal surface, the margin of the body being delimited by the superomarginals; on the arms both superomarginals and inferomarginals reach the same vertical plane. The inferomarginals are slightly shorter than the superomarginals; in the center of the interbrachial are the two series correspond, but from the arm bases outward the former alternate more or less with the latter. The inferomarginals bear pedicellariae similar to those on the superomarginals, mostly situated near the intermarginal suture.

Both superomarginals and inferomarginals are somewhat tumid, and both are covered with small closely packed hemispherical granules.

The actinal intermediate plates are very numerous and decrease in size from the adambulacral series toward the center of the interbrachial arc; those adjoining the adambulacrals are relatively large and regular in arrangement; within these there is a more or less regular second row which may be traced for about half of the distance to the 
arm bases; but within and beyond these the plates are small, irregularly polygonal, and with no obvious arrangement. All of the actinal intermediate plates are slightly tumid and are uniformly covered with crowded granules; many bear pedicellariae, of which those on the plates adjoining the adambulacrals are conspicuously larger than the others; a plate in this series may bear as many as four pedicellariae. At the oral angle of the interradial area there is usually a large odd plate which may bear as many as six pedicellariae.

The adambulacral plates are about as long as broad, becoming proportionately longer distally; the furrow border is angular; the furrow series consists of from 10 to 15 flattened spines, the outer flattened parallel with, the inner transverse to, the furrow; within these there is a bare area, followed by a row of from four to five prominent stout spines, beyond which are numerous tubercles decreasing in size toward the outer edge of the plate. Most of the adambulacral plates bear one, proximally often two, large high pedicellariae on the inner part near the proximal border.

The mouth plates are small; each of them bears from 12 to 15 very stout flattened spines along the furrow, and a half dozen or more short spines, either forming a single row along the suture line, or more irregularly arranged, on the actinal surface.

Mariaster differs markedly from Johannaster in the lack of regularity in the arrangement of the actinal intermediate plates, in the absence of spines on the same plates, and in several other important features. It agrees more nearly with Lydiaster and Circeaster (especially the former), showing its relationship in the character and arrangement of the actinal intermediate plates, in the character of the armament of the adambulacral plates, in the character and distribution of the pedicellariae, in the form and size of the madreporite, and in other ways; it differs most strikingly from these genera in having narrower and longer arms on which the abactinal plates are not conspicuously larger than those of the disk.

The single species referable to this genus, Mariaster giganteus (Goto), is known only from near Misaki, Sagami Bay, Japan, in from 160 to 1120 meters. Five specimens in all are known to have been collected, four of which are in the museum of the Science College at Tokyo.

\section{Pseudonepanthia, new genus}

Genotype.-Pseudonepanthia Gotoi, new species.

The characters of this new genus, which appears to be referable to the family Asterinidae and the subfamily Asterininae, are included in those of the type species, the description of which follows:

\section{Pseudonepanthia Gotoi, new species}

Eight arms; $R=72 \mathrm{~mm}$. $; \mathrm{r}=11 \mathrm{~mm}$. $\mathrm{R}: \mathrm{r}=6.5: 1$; inferomarginals 111 .

The rays are very long and narrow, almost circular in cross section, evenly tapering to the tip; only three are of full size, the remainder 
being very small; two of the very small rays alternate between the three of full size; the other three are side by side between two of the later.

The gonads extend to the ninth superomarginal.

The interbrachial septum is very deep, extending from the stomach to the lateral interradial body wall, and is membranous except for a broad centrally situated pillar composed of large overlapping plates.

Prominent superambulacral plates are present.

The pedicels are in two rows; they carry large sucking disks and are connected internally with double ampullae.

The plates of the abactinal surface are very numerous, greatly reduced in size, narrow, crescentic with swollen and rounded ends, imbricating outward in the median line and perpendicularly to the midradial line elsewhere. Three parallel rows of larger plates occupy the mid-dorsal line of the arms; from the outer of these on either side the smaller plates extend in regular diagonal rows to the superomarginals, in such a manner that the diagonal rows arising at any one point in the median line run both distally and proximally at the same angle with the superomarginals, while the plates of the succeeding rows also form straight and regular transverse rows between, and perpendicular to, the mid-dorsal rows and the superomarginals with which, however, they do not quite coincide.

Externally the lateral plates appear as crescents regularly decreasing. in size from the dorsal region to the margin, each crescent partially surrounding a single large papula situated in its concavity, on its abactinal side; the plates of the median rows, while commonly crescentic with the concavity proximal, may be triangular or irregular in shape. The plates of the disk are irregular; most of them are of about the same size as the median plates of the arms, but they become smaller about the anal opening.

To the naked eye the appearance of the abactinal skeleton is somewhat similar to that in such species of Henricia as H. leviuscula, though the arrangement of the plates is much more regular.

The surface of the abactinal plates is thickly beset with numerous fine spines, of which the larger may bear from 20 to 25 . In the proximal third to half these spines are stout, rounded-conical, with a dull surface, but the distal portion is glassy and transparent, in lateral view increasing in diameter at first slowly, later more rapidly, to the coarsely serrate tip, so that they appear narrowly fan-shaped; in end view they are seen to consist of three very delicate glassy calcareous laminae united by their inner edges.

The papulae are large and conspicuous, decreasing in size from the mid-dorsal region of the arms to the superomarginals; they are arranged in very regular diagonal, and also transverse, rows. They are absent from the region between the central portion of the disk and patches at the base of the arms, and from a region including the actinal half of each interbrachial angle and extending thence in a long triangle to about the eighteenth inferomarginal. On the arms there is one papula 
in the concavity of each of the crescentic abactinal plates, except in the mid-dorsal line, where some plates may be without them, and at the end of the arms, where they occur in a single line on either side of the median line, and a quadruple, later triple and double, line just above the superomarginals. The tip of the arm is entirely without papulae. On the disk papulae occur one to a plate in a more or less triangular area within each arm base; scattered papulae occur in the center of the disk.

In the proximal three-fourths of the arm the superomarginals correspond with the inferomarginals, and are of about the same size; in the distal fourth of the arm they become irregular in position and indistinguishable from the abactinal plates; at first they are narrow and transversely oblong, becoming triangular after the fourteenth. Their armature is the same as that of the abactinal plates, from which they are distinguishable only by their shape.

The inferomarginals, 111 in number, are at first longitudinally oblong, becoming squarish at the middle of the arm, and transversely oblong distally; their armature resembles that of the superomarginals.

The actinal intermediate areas are narrow; the plates are arranged in rows parallel to the furrows; one row reaches to the distal fourth of the arm, or possibly beyond; a second reaches the 25th inferomarginal; the third reaches the twelfth inferomarginal; the fourth extends to the seventh superomarginal; and the fifth to the fifth; beyond the fifth row there are a few additional plates. The armature consists of from 7 to 16 (usually about 12) well spaced sacculate spines with fluted and spinous sides, ending in a tuft of spinelets. On the arms the spines on the actinal intermediate plates resemble those on the abactinal plates rather than those on the interradial regions of the disk (just described), but are larger and longer.

The armature of the adambulacral plates consists of four or five long furrow spines, the inner very slightly the longer, set in a slightly curved comb; beyond these there is a row of four or five spines resembling those on the actinal intermediate plates, but somewhat longer and stouter; this row is rather more strongly curved than the furrow series and is placed diagonally, so that the proximal end is farther from the groove than the distal; this obliquity decreases distally and is not noticeable in the outer two thirds or half of the arm; beyond this second row there are a few additional shorter spines, not distinguishable from those on the adjacent actinal intermediate plates.

The mouth plates are small, bearing on the furrow margin five long flattened spines decreasing in length and stoutness outwardly; these spines are finely fluted, with saw teeth on the ridges; within this furrow series is a second series of five similar but shorter spines; the remainder of the surface of the mouth plates bears four or five spaced spines similar to those on the actinal intermediate plates.

Color in alcohol dark reddish brown.

Type.-Cat. No. 36899, U. S. N. M., from "Albatross" Station 3746, Sagami Bay, Japan, in 49 fathoms. 
Glabraster, new genus

Genotype.-Porania magellanica Studer, 1876.

This new genus is referable to the family Echinasteridae. The whole animal in enclosed in a thick skin which entirely conceals the plates and all but the tips of the spines; this investment carries minute scattered spicules.

The ampullae are single.

The gonads are attached to the dorsal wall on either side of the interbrachial septum.

The interbrachial septum is complete and rather large, though entirely membranous; it is crossed in the middle, in a line more or less parallel to its curved inner border, by a narrow band of elongate calcareous ossicles placed end to end and not always touching, which actinally curves inward and runs adorally to the mouth plates. This band is more or less interrupted and may be present only in part.

The first ambulacral ossicle is much larger than those succeeding and is widely forked in its proximal half.

The abactinal skeleton is very wide-meshed, reticulate, formed of very narrow elongate overlapping plates with usually pentalobate spiniferous plates at the more important nodes.

There is a central pentalobate plate, the lobes being radial in position, which bears a prominent conical spine; in each interradius about one third of the distance between the central plate and the marginals there is a similar spiniferous pentalobate plate; these five spiniferous pentalobate plates about the central abactinal plate are connected by narrow lines of plates, and from the middle of each of these lines a similar line (radial in position) runs to the central plate; also from each of these five interradial lobate plates lines of plates run out on either side parallel to the interbrachial margin, those from adjacent plates uniting at an obtuse angle in the mid-radial line, so that five triangies which are about twice as wide as high are formed, of which the lines directly connecting the interradial pentalobate plates are the bases. From the apex of each of these triangles, which is marked by a pentalobate plate bearing a small spine, a more or less irregular series of from four to seven similar spiniferous lobate plates runs down the mid-dorsal line of each arm; these plates are connected in the middorsal line by low elongate plates. From the large spiniferous lobate plates in each interradius a double series consisting of five pairs of elongate plates runs to the marginals; the second pair beyond the lobate plate consists of plates with the adcentral ends broadened, and from these there runs to the proximal mid-radial lobate plate at the arm base a series of narrow plates; from a point midway on this series to the arm tips there is a very irregular interrupted series of similar but smaller plates, from which lines of plates run to each superomarginal and to each node in the mid-radial line.

Within the wide meshes between the very narrow lines of plates are large papular areas, the integument of which is abundantly dotted with calcareous granules. 
The anal opening, which is large and surrounded with short spines, lies near the apical spiniferous plate.

The madreporite is a separate skeletal element lying between the plates of the first pair below the large lobate plate at the base of the interradial area.

The superomarginals are trilobed and strongly imbricating; in the proximal two thirds of the arm the imbrication is toward the center of the interbrachial arc, in the distal two thirds it is toward the arm tips; a quadrilobate plate imbricating both ways marks the transition.

Except for slightly greater size the inferomarginals are not different from the plates forming the outermost row of the actinal intermediate series, just within them; they are much broader than long in the interbrachial are, but increase in length outwardly; their imbrication which is slight, is outward. Each inferomarginal bears a prominent flattened spine with a truncated gouge-shaped tip, except for the three or four in the center of the interbrachial arc which bear two similar but smaller spines.

The actinal intermediate plates are elongate, imbricating adcentrally, arranged in regular bands between the inferomarginals and the adambulacrals which correspond to the former but not to the latter. The plates composing these lines form about five regular transverse rows. The row adjoining the inferomarginals has an additional plate in the center. There are no actinal papulae.

The adambulacral plates have a prominent, slender, sharp-pointed spine deep in the furrow, and a much longer and stouter chisel-shaped spine with a truncated gouge-shaped tip on the inner border of the actinal surface; in the terminal portion of the arm there are two of these latter to each plate instead of one.

The mouth plates bear two long flattened spines distally, which increase in diameter to the truncated tip, and a similar spine at the border of the first adambulacrals.

Glabraster magellanica (Studer) is confined to the Magellanic region, occurring in the Straits of Magellan and along the shores of Patagonia from the shore line down to 45 fathoms; Glabraster antarctica (E. A. Smith), the only other species of the genus, is known from Kerguelen, Marion Island, Prince Edward Island, the Crozet Islands, and South Georgia, in from 50 to 1600 fathoms. 


\section{$2 \mathrm{BHL}$ Biodiversity Heritage Library}

Clark, Austin Hobart. 1916. "Seven new genera of echinoderms." Journal of the Washington Academy of Sciences 6, 115-122.

https://doi.org/10.5962/bhl.part.10912.

View This Item Online: https://www.biodiversitylibrary.org/item/18393

DOI: https://doi.org/10.5962/bhl.part.10912

Permalink: https://www.biodiversitylibrary.org/partpdf/10912

\section{Holding Institution}

MBLWHOI Library

\section{Sponsored by}

MBLWHOI Library

\section{Copyright \& Reuse}

Copyright Status: Public domain. The BHL considers that this work is no longer under copyright protection.

This document was created from content at the Biodiversity Heritage Library, the world's largest open access digital library for biodiversity literature and archives. Visit BHL at https://www.biodiversitylibrary.org. 